\title{
DESENVOLVIMENTO, CARACTERIZAÇÃO MORFOLÓGICA E CRISTALOGRÁFICA DE SISTEMAS MULTICOMPONENTES COM O ACETATO DE HECOGENINA
}

\section{C.D.L.F.A.MOREIRA ${ }^{1}$, W.F.SILVA-JÚNIOR, J.G.O.PINHEIRO, L.J.QUINTANS- JÚNIOR, A.A.S.ARAÚJO, A.A.N.LIMA}

\author{
${ }^{1}$ Universidade Federal do Rio Grande do Norte, Centro de Ciências da Saúde, Departamento \\ de Farmácia \\ ${ }^{2}$ Universidade Federal de Sergipe, Departamento de Fisiologia \\ carlosdemocedes@gmail.com
}

\begin{abstract}
RESUMO - O acetato de hecogenina consiste em uma sapogenina com atividade antihiperalgésica que apresenta solubilidade limitada. Visando o incremento de tais propriedades o desenvolvimento de sistemas multicomponentes com ciclodextrinas e polímeros hidrofilicos é interessanto. O objetivo desse estudo é desenvolver tais sistemas com os polímeros PEG, PVP e HPMC, caracterizá-los quanto a morfologia e cristalinidade para avaliar como tais sistemas podem melhorar as propriedades físico-químicas do protótipo. Os sistemas foram obtidos pelos métodos de mistura física e malaxagem e a caracterização foi realizada pelos métodos de DRX e MEV. Os resultados da Cristalografia mostraram o comportamento cristalino com altas reflexões e de alta intensidade, tais reflexões tendem a diminuir com a formação desses sistemas. Já os resultados da microscopia mostram a alteração morfológica dos cristais do protótipo. Logo, é possivel concluir que tais sistemas são interessantes para melhorar as propriedades fisico-quimicas do acetato de hecogenina.
\end{abstract}

Palavras-chave: Acetato de hecogenina, sistemas multicomponentes, MEV, DRX.

ABSTRACT: Hecogenin acetate consists of a sapogenin with antihyperalgesic activity that has limited solubility. In order to increase these properties the development of multicomponent systems with cyclodextrins and hydrophilic polymers is interesting. The aim of this study is to develop such systems with the PEG, PVP and HPMC polymers, to characterize them as morphology and crystallinity to evaluate how such systems can improve the physicochemical properties of the prototype. The systems were obtained by the methods of physical mixing and malaxation and the characterization was performed by the XRD and SEM methods. The results of Crystallography showed the crystalline behavior with high reflections and high intensity, such reflections tend to decrease with the formation of these systems. The results of the microscopy show the morphological alteration of the crystals of the prototype. Therefore, it is possible to conclude that such systems are interesting for improving the physico-chemical properties of hecogenin acetate. 


\section{INTRODUÇÃO}

A Indústria Farmacêutica vem buscando novas alternativas terapêuticas derivadas de produtos naturais para condições clínicas onde o tratamento com fármacos tradicionais já não são efetivos. Trazendo esse contexto para as plantas do Sertão Nordestino temos a planta Agave sisalana, conhecida popularmente como sisal apresenta uma grande quantidade de sapogeninas em seu sulco, onde a mais relevante é a hecogenina (BOTURA, 2013). A acetilação dessa substância é encontrada como o produto acetato de hecogenina, cujas atividades biológicas já são elucidadas como, gastroprotetora (CERQUEIRA, 2012) e antihiperalgésica (QUINTANS, 2015). Entretanto, devido à baixa solubilidade há uma dificuldade de desenvolvimento de formulações sólidas orais para esse protótipo. Tendo em vista esse problema, o desenvolvimento de sistemas multicomponentes com ciclodextrinas e polímeros hidrofílicos, como agentes ternários, são alternativas interessantes (LOFTSSON E BREWSTER, 2012). O presente estudo visa desenvolver tais sistemas com os polímeros PEG 6000, PVP K-30 e HPMC, caracterizá-los com relação a morfologia e cristalografia e depois avaliar como a adição do polímero como terceiro componente influencia na complexação do acetato de hecogenina com a betaciclodextrina.

\section{MATERIAIS E MÉTODOS}

$\mathrm{O}$ acetato de hecogenina, beta-ciclodextrina, PVP K-30 e HPMC foram comprados a Sigma Aldrich, enquanto o PEG 6000 foi comprado a Quemis. Todos os reagentes utilizados no estudo foram de grau analítico. Os sistemas foram obtidos pelos métodos de mistura física e malaxagem nas razões molares de $1: 1$ e $1: 2 \mathrm{com} 2,5 \%$ de cada polímero. A caracterização morfológica foi realizada pela Microscopia Eletrônica de Varredura (MEV), onde as amostras foram colocadas sob dupla fita de carbono carbono e analisada utilizando o equipamento modelo Hitachi Tabletop Microscope TM3000 e voltagem de $15 \mathrm{kV}$. Enquanto a caracterização cristalográfica por Difração de Raios-X (DRX) pelo Bruker D2 Phaser utilizando radiação CuK $\alpha(\lambda=1,54 \AA)$ com um filtro de $\mathrm{Ni}$, com passo de $0,02^{\circ}$, corrente de $10 \mathrm{~mA}$, voltagem de $30 \mathrm{kV}$, utilizando um detector Lynxeye.

\section{RESULTADOS E DISCUSSÃO}

Figura 1: Difratogramas dos sistemas multicomponentes com o HPMC (A), PVP(B) e PEG(C)

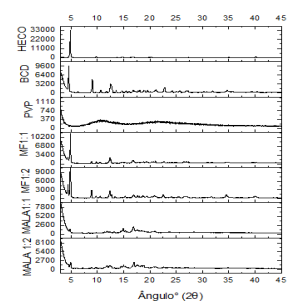

A

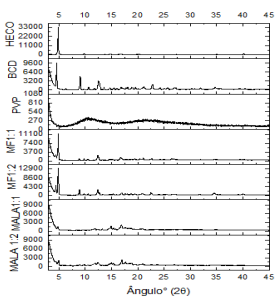

B

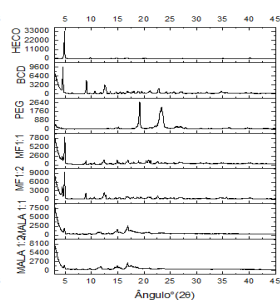

C

A análise de difração de raios-X do Acetato de hecogenina isolado evidencia o comportamento cristalino dessa substância, partindo da premissa de que materiais 
cristalinos são capazes de difratar os raios-X. De acordo com o difratograma, é visível uma reflexão cristalina de altíssima intensidade, cerca de 32380, na região de aproximadamente $5^{\circ}$, tais resultados coincidem com resultados já observados na literatura (MOREIRA, 2018). Ao analisar os gráficos do difratograma da betaciclodextrina foi perceptível que, a betaciclodextrina apresenta um difratograma característico de material cristalino já que ele apresenta reflexões cristalinas de intensidade considerável, assim como o polímero PEG também apresenta características de material cristalino também devido duas reflexões cristalinas no meio do gráfico do difratograma. Já ao avaliar todos os gráficos dos sistemas multicomponentes obtidos por Mistura física, é possível se dizer que mesmo esse método sendo simples há uma redução muito pequena da cristalinidade que se torna irrelevante, havendo apenas uma exceção que é para o sistema multicomponente Acetato de hecogenina + betaciclodextrina $(1: 2)+$ HPMC, onde houve uma redução bastante acentuada da cristalinidade. Já ao avaliar rodos os sistemas obtidos pelo método de malaxagem é perceptível que há uma redução bastante considerável em praticamente todos os sistemas com todos os polímeros e em ambas as proporções, favorecendo a conclusão de que esse método de obtenção é eficiente para se desenvolver esses sistemas, apesar da sua simplicidade.

Figura 2: Fotomicrografias dos sistemas multicomponentes com o HPMC(A), PVP e $\operatorname{PEG}(\mathrm{C})$

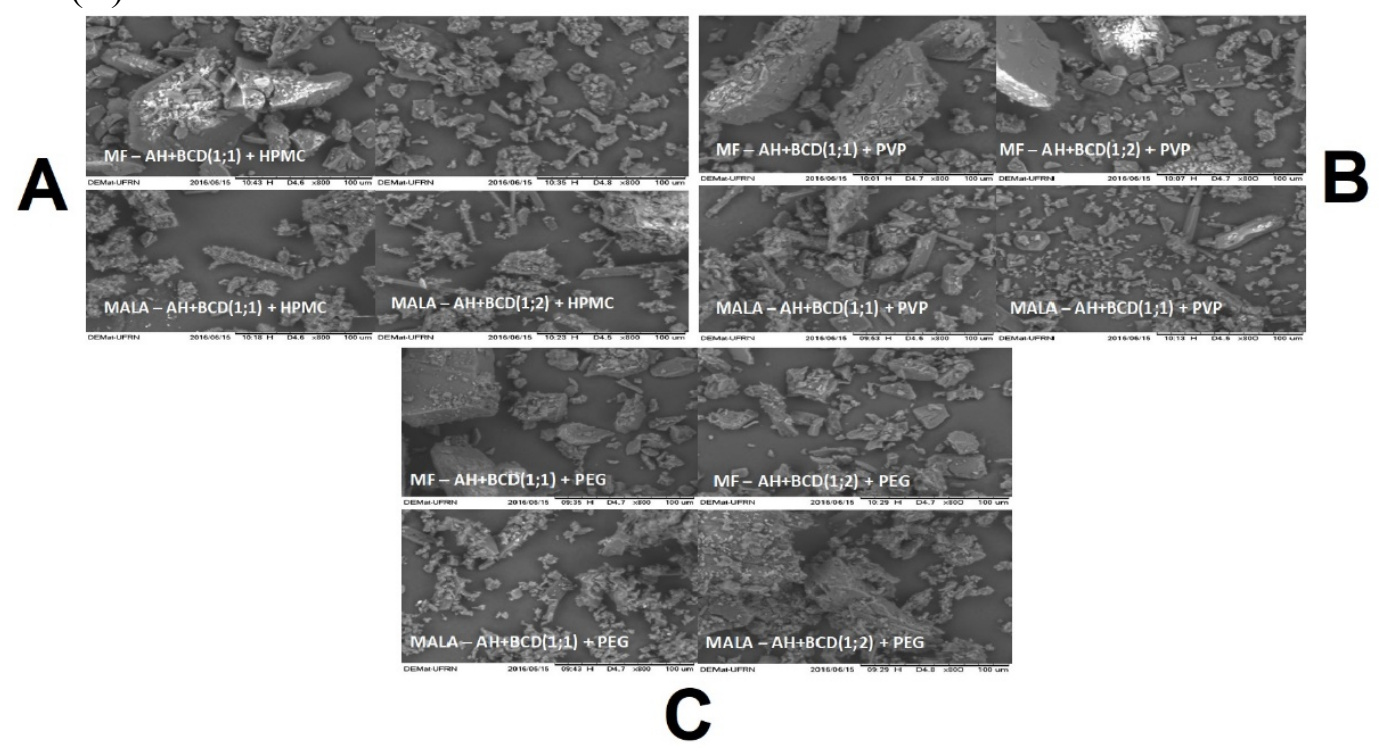

Já a análise de morfologia de superfície pela Microscopia Eletrônica de Varredura, foi perceptível avaliar que o acetato de hecogenina apresenta uma característica cristalina onde sua superfície é lisa e as extremidades são irregulares, característica de cristais monoclínico simples (QUINTANS, 2016) os sistemas obtidos por mistura física, ainda há resquícios dos cristais tanto do acetato de hecogenina quanto da beta-ciclodextrina, provando que esse método de obtenção não é interessante para se desenvolver esses sistemas. Sendo que, ao avaliar os sistemas obtidos pelo método de malaxagem, é possível observar no campo que há uma alteração morfológica considerável em praticamente todos os sistemas, tanto com o HPMC, PVP e PEG obtidos na proporção de 1:1 e de 1:2. Provando que esse método é mais eficiente para se obter os sistemas multicomponentes e consequentemente incrementar a complexação do acetato de hecogenina na betaciclodextrina. 


\section{CONCLUSÃO}

INOVAÇÃO TERAPEUUTICA

Logo, de acordo com as análises feitas no estudo, podemos concluir que os sistemas multicomponentes formados pelo complexo acetato de hecogenina/beta-ciclodextrina e polímeros hidrofílicos são tornam alternativas interessantes para incrementar a eficiência de complexação e seus parâmetros físico-químicos como solubilidade estabilidade e sua atividade farmacológica em si.

\section{REFERÊNCIAS}

BOTURA, M. B., dos Santos, J. D. G., Silva, G. D., Lima, H. G., Oliveira, J. V. A., Almeida, M. A. O., Batatinha, M. J. M., Branco, A., 2013. In vitro ovicidal and larvicidal activity of Agave sisalana Perr. (sisal) on gastrointestinal nematodes of goats. Vet. Parasit. 192(1-3), 211-217.

CERQUEIRA, G. S., Silva, G. S., Vasconcelos, E. R., Freitas, A. P. F., Moura, B. A., Macedo, D. S., Souto, A. L., Barbosa-Filho, J. M., Leal, L. K. A., Brito, G. A. C., Souccar, C., Viana, G. S. B. (2012). Effects of hecogenin and its possible mechanism of action on experimental models of gastric ulcer in mice. Eur J Pharm. 683(1-3), 260269.

QUINTANS, Jullyana SS et al. Evidence for the involvement of spinal cord-inhibitory and cytokines-modulatory mechanisms in the anti-hyperalgesic effect of hecogenin acetate, a steroidal sapogenin-acetylated, in mice. Molecules, v. 19, n. 6, p. 8303-8316, 2014.

HOSTETTMANN, Kurt; MARSTON, Andrew. Saponins. Cambridge University Press, 2005.

LOFTSSON, Thorsteinn; BREWSTER, Marcus E. Cyclodextrins as functional excipients: methods to enhance complexation efficiency. J pharm sci, v. 101, n. 9, p. 3019-3032, 2012.

MOREIRA, Carlos Demócedes Luís de França Almeira et al. Amorphous solid dispersions of hecogenin acetate using different polymers for enhancement of solubility and improvement of anti-hyperalgesic effect in neuropathic pain model in mice. Biomed Pharmacother. v97, p.870-879, 2018.

QUINTANS, J. S. S., Pereira, E. W. M., Carvalho, Y. M. B. G., Menezes, P. M., Serafini, M. R., Batista, M. V. A., Moreira, C. D. L. F. A., Lima, A. A. N., Branco, A., Almeida, J. R. G. S., Gelain, D. P., Zengin, G., Araújo, A. A. S., Quintans-Júnior, L. J., 2016. Hostguest inclusion complexation of $\beta$-cyclodextrin and hecogenin acetate to enhance antihyperalgesic effect in an animal model of musculoskeletal pain. Process Biochem 